\title{
A high-efficiency continuous class-F power amplifier design using simplified real frequency technique
}

\author{
Md. Golam Sadeque, Zubaida Yusoff, Mardeni Roslee \\ Faculty of Engineering, Multimedia University, Persiaran Multimedia, 63100 Cyberjaya, Malaysia
}

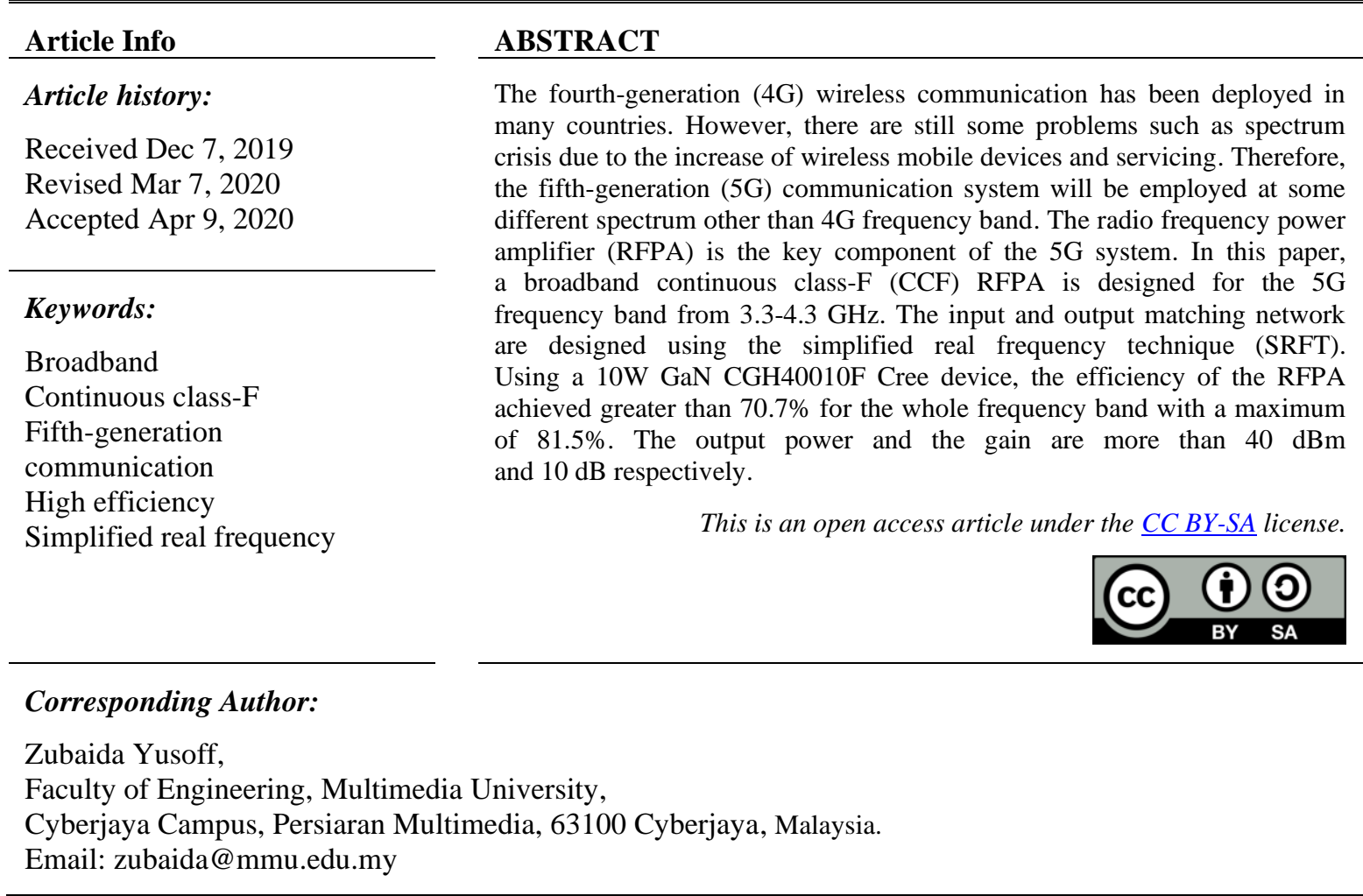

\section{INTRODUCTION}

With the evolution of wireless technology, the use of wireless devices increasing day by day in different fields. Likewise, the requirement of the communication speed and bandwidth of the system are also increased. To meet the demand of the users, the next fifth-generation (5G) communication system will be implemented very soon. The upcoming $5 \mathrm{G}$ network has a large bandwidth and high data rates facilities which can be deployed for multimedia application. The $5 \mathrm{G}$ system will operate mainly in two frequency bands: low-frequency band up to $6 \mathrm{GHz}$ and high-frequency band from 24 to $86 \mathrm{GHz}$ [1]. In the low-frequency band, the communication network of different countries will operate at different operating frequencies. The nominated frequency bands of some countries are shown in Table 1 [2, 3]. From Table 1, it is seen that the lowest frequency is $3.3 \mathrm{GHz}$ and the highest frequency is $4.2 \mathrm{GHz}$.

The crucial component of a wireless communication system is the radio frequency power amplifier (RFPA) [4]. The RFPA is used in the transceiver and usually consume largest power compare to the other components [5]. RFPAs are divided basically into two types: the biasing class and the switching class [6]. In the biasing class, the RFPA is classified such as Class A, B, AB and C depending on their current conduction angle. The switching class RFPA turn on and off are controlled by the input signal. Some examples of switching class RFPA are Class D, E, F J, H and S. Two widely used switching RFPA are class-E and class-F. These two RFPA are used because it can achieve high efficiency. Nevertheless, at the high frequency, the efficiency of the class-E amplifier decreases because of the limitation of charging capacity [7]. Whereas in case of a class-F amplifier, there is no charging limitation problem. In addition, the theoretical efficiency $100 \%$ can be achieved by properly terminating infinite 
number of harmonics at the output. The class-F RFPA is a good choice for narrowband applications but not suitable for large band applications [8]. To alleviate the narrow band problem, waveform engineering-based continuous class-F (CCF) RFPA technique has been applied. However, there is a problem of anticlockwise rotation of fundamental and harmonics impedance at the current generator plane [9] when using this technique. The anticlockwise impedance rotation is not possible to realize using a matching network. By carefully selecting the optimum impedance at the generator plane this problem can be solved.

Table $1.5 \mathrm{G}$ spectrum allocation of different countries in the low-frequency band

\begin{tabular}{|c|c|c|c|c|c|c|c|c|c|c|c|}
\hline Country & USA & Finland & France & Germany & Ireland & Italy & Russia & Spain & $\begin{array}{c}\text { United } \\
\text { Kingdom }\end{array}$ & China & Japan \\
\hline $\begin{array}{c}\text { Frequency } \\
(\mathrm{GHz})\end{array}$ & $\begin{array}{c}3.55-3.7 \\
3.7-4.2 \\
\end{array}$ & $3.4-3.8$ & $3.46-3.8$ & $3.4-3.8$ & $3.4-3.8$ & $3.6-3.8$ & $3.4-3.8$ & $3.4-3.8$ & $\begin{array}{l}3.4-3.6 \\
3.6-3.8 \\
\end{array}$ & $3.3-3.6$ & $3.6-4.2$ \\
\hline
\end{tabular}

In this paper, a broadband CCF RFPA is designed for the frequency range of 3.3 to $4.3 \mathrm{GHz}$. The simplified real frequency technique (SRFT) has been used for the designing of input and output matching networks. In section II, the theory of CCF RFPA is discussed. The methodology of the designing of the CCF amplifier is proposed in section III. Section IV represents the simulated result of the designed PA. Finally, conclusions are presented in section V.

\section{THEORY OF CCF MODE}

The conventional class-F mode RFPA is derived from the class-B amplifier by properly terminating the harmonics impedance. The output matching network is designed in such a way that it provides short circuit termination at even harmonics and open circuit termination at odd harmonics. Thus, conventional class-F RFPA provide half rectified sine wave and square shape voltage wave. The ideal class-F power amplifier provide the non-overlap between voltage and current [10]. Therefore, the theoretical efficiency of conventional class-F RFPA is $100 \%$. The conventional class-F amplifier provides better performances for narrowband application but it is not suitable for the wideband application. The latest technique for achieving good performance for the wideband applications is continuous class-F (CCF) RFPA. For the case of CCF RFPA, the drain voltage waveform is multiplied by the term $(1-\gamma \sin \theta)$. Then, the equation of the drain voltage and current waveform can be written as follows [11]

$$
\begin{aligned}
& v_{D}=\left(1-\frac{2}{\sqrt{3}} \cos \theta\right)^{2}\left(1+\frac{1}{\sqrt{3}} \cos \theta\right)(1-\gamma \sin \theta) \\
& i_{D}=\frac{1}{\pi}+\frac{1}{2} \cos \theta+\frac{2}{3 \pi} \cos 2 \theta-\frac{2}{15 \pi} \cos 4 \theta+\frac{2}{35 \pi} \cos 6 \theta+\cdots
\end{aligned}
$$

The value of $\gamma=0$ corresponds to the conventional class-F power amplifier. By changing the value of the $\gamma$ from -1 to 1 a family of voltage curves obtained that provide the new design space for RFPA design [12]. The performances of the new type of RFPA are the same for every value of $\gamma$ between this range. The fundamental and harmonics impedances of the CCF power amplifier are calculated from the ratio of drain voltage and drain current. The first three harmonics impedance of the CCF RFPA is as follows:

$$
\begin{aligned}
& Z_{F}=R_{o p t} \frac{2}{\sqrt{3}}+j R_{o p t} \gamma \\
& Z_{2, F}=-j R_{o p t} \frac{7 \sqrt{3} \pi}{24} \gamma \\
& Z_{3, F}=\infty
\end{aligned}
$$

When $\gamma$ is varied from -1 to +1 then the locus of fundamental impedances rotate in the clockwise direction and second harmonics impedances are rotating in anticlockwise direction but the third harmonic remain standstill at infinite impedance point as shown in Figure 1. Therefore, the broadband RFPA can be achieved by designing the matching network that follows the fundamental and harmonics impedance locus. 


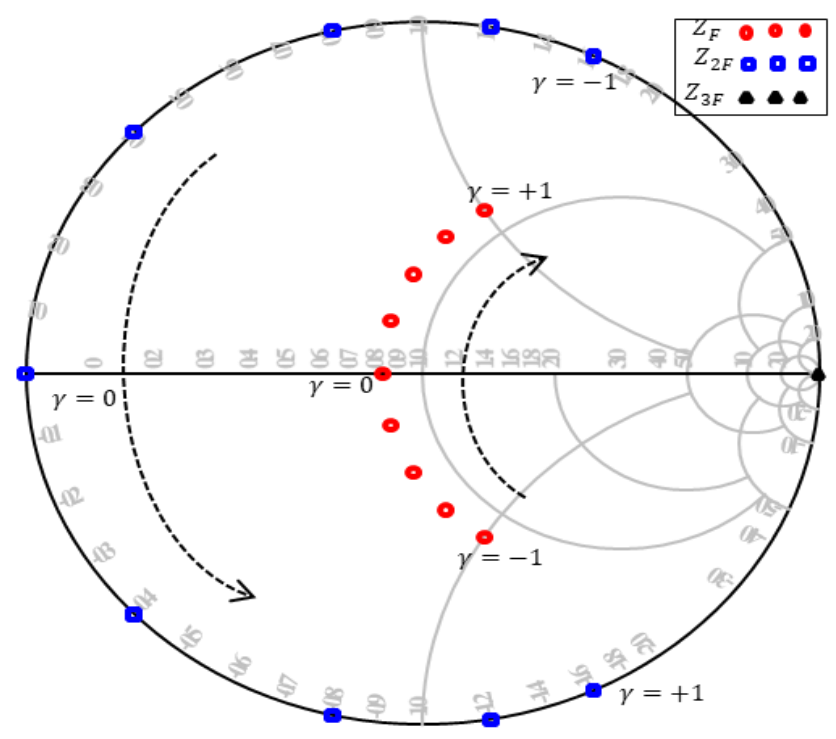

Figure 1. Impedance locus of first three harmonics impedance

\section{BROADBAND CCF AMPLIFIER SYNTHESIS AND DESIGN}

The design of CCF RFPA is conducted by using the nonlinear model of the CGH40010 10W gallium nitride (GaN) HEMT device from the CREE company. Load pull and source pull are a widely used technique in the design of the RFPA. It allows us to find the optimum impedance at the desired frequency considering the performances such as efficiency, gain and output power. This amplifier is designed for the $5 \mathrm{G}$ frequency range from 3.3 to $4.3 \mathrm{GHz}$. The load-pull and source pull method are applied to find optimum impedance in the whole frequency band with a spacing $100 \mathrm{MHz}$. The optimum impedance values for fundamental, second harmonics and third harmonics are shown in Table 2. The single matching problem occurs when the generator impedance is resistive while the load impedance is complex. Since this RFPA is designed for the $50 \Omega$ input and output reference impedance while the optimum source and load impedance are complex, so this case is a single matching problem. The distributed SRFT algorithm is applied to fit the fundamental load impedances well as the second and third harmonics impedance [13].

Table 2. The optimum impedances obtained from load-pull and source pull technique

\begin{tabular}{cccccccccc}
\hline frequency & $Z_{L 1}$ & $Z_{L 2}$ & $Z_{L 3}$ & $Z_{S 1}$ & $Z_{S 2}$ & $Z_{S 3}$ & Gain & $P_{\text {out }}$ & PAE \\
\hline 3.3 & $14.4+\mathrm{j} 13.5$ & $-2.7-\mathrm{j} 0.19$ & $71+\mathrm{j} 839$ & $1.9-\mathrm{j} 11.4$ & $1.9-\mathrm{j} 11.4$ & $1.9-\mathrm{j} 11.4$ & 10.64 & 40.64 & 76.38 \\
3.4 & $14+\mathrm{j} 12.2$ & $0.4-\mathrm{j} 2$ & $71+\mathrm{j} * 839$ & $1.8-\mathrm{j} 12.2$ & $1.7-\mathrm{j} 12.3$ & $1.8-\mathrm{j} 12.1$ & 10.02 & 40.02 & 66.4 \\
3.5 & $8.4+\mathrm{j} 7.4$ & $0.15+\mathrm{j} 2$ & $71+\mathrm{j} 839$ & $1.6-\mathrm{j} 13.2$ & $1.7-\mathrm{j} 12.3$ & $1.9-\mathrm{j} 11.4$ & 10.15 & 40.15 \\
3.6 & $8.9+\mathrm{j} 5.4$ & $0.15+\mathrm{j} 2$ & $71+\mathrm{j} 839$ & $1.6-\mathrm{j} 14.0$ & $1.7-\mathrm{j} 12.3$ & $1.9-\mathrm{j} 11.4$ & 10.73 & 40.73 & 75.00 \\
3.7 & $9.2+\mathrm{j} 3.4$ & $0.15-\mathrm{j} 2$ & $70.5+\mathrm{j} 839$ & $1.3-\mathrm{j} 14.8$ & $1.7-\mathrm{j} 12.3$ & $1.9-\mathrm{j} 11.4$ & 11.19 & 41.192 & 76.68 \\
3.8 & $9.2+\mathrm{j} 3.4$ & $0.15-\mathrm{j} 2$ & $70.5+\mathrm{j} 839$ & $1.1-\mathrm{j} 15.9$ & $1.7-\mathrm{j} 12.3$ & $1.9-\mathrm{j} 11.4$ & 10.93 & 40.93 & 78.19 \\
3.9 & $9.2-\mathrm{j} 3.4$ & $0.15-\mathrm{j} 2$ & $70.5+\mathrm{j} 839$ & $1.3-\mathrm{j} 17.7$ & $1.7-\mathrm{j} 12.3$ & $1.9-\mathrm{j} 11.4$ & 10.42 & 40.42 & 77.41 \\
4 & $11.0+\mathrm{j} 2.8$ & $0.15-\mathrm{j} 2$ & $70.5+\mathrm{j} 839$ & $1.2-\mathrm{j} 18.3$ & $1.7-\mathrm{j} 12.3$ & $1.9-\mathrm{j} 11.4$ & 10.12 & 40.12 & 72.00 \\
4.1 & $9.4-\mathrm{j} 2.6$ & $0.15-\mathrm{j} 2$ & $70.5+\mathrm{j} 839$ & $1.2-\mathrm{j} 19.1$ & $1.7-\mathrm{j} 12.3$ & $1.9-\mathrm{j} 11.4$ & 10.28 & 40.28 & 76.11 \\
4.2 & $8.1+\mathrm{j} 1.15$ & $0.15-\mathrm{j} 2$ & $70.5+\mathrm{j} 839$ & $1.2-\mathrm{j} 20.0$ & $1.7-\mathrm{j} 12.3$ & $1.9-\mathrm{j} 11.4$ & 10.13 & 40.13 & 75.93 \\
4.3 & $9.8-\mathrm{j} 1.7$ & $0.15-\mathrm{j} 2$ & $70.5+\mathrm{j} 839$ & $1.6-\mathrm{j} 20.5$ & $1.7-\mathrm{j} 12.3$ & $1.9-\mathrm{j} 11.4$ & 11.53 & 41.53 & 75.34 \\
\hline
\end{tabular}

$Z_{L 1}$ : Load impedance at the fundamental frequency, $Z_{L 2}$ : Load impedance at $2^{\text {nd }}$ harmonics, $Z_{L 3}$ : Load impedance at $3^{\text {rd }}$ harmonics, $Z_{S 1}$ : Load impedance at the fundamental frequency, $Z_{S 2}$ : Source impedance at $2^{\text {nd }}$ harmonics, $Z_{S 3}$ : Load impedance at $3^{\text {rd }}$ harmonics, $P_{\text {out }}$ : Output power in $\mathrm{dBm}$. PAE: power aided efficiency

\subsection{Simplified real frequency technique (SRFT)}

The SRFT algorithm was first developed by the Yarman and Carlin which was mainly focused on the lump elements LC network synthesis. The SRFT algorithm was then evolved and modified for the distributed network synthesis. In the SRFT algorithm, the input reflection coefficient of the matching network $S_{11}(p)$ can be represented as [14-17]

$$
S_{11}=\frac{h(p)}{g(p)}=\frac{h_{0}+h_{1} p+\cdots+h_{n} p^{n}}{g_{0}+g_{1} p+\cdots+g_{n} p^{n}}
$$


where $h(p)$ and $g(p)$ are the polynomials of order $\mathrm{n}$. The order of the polynomial determines the total number of reactive elements in the matching network. The other scattering parameter $S$ of the matching network (which is also known as the equalizer), can be determined from the $S_{11}$ by employing the Belevitch representation shown in (5) and (6).

$$
\begin{aligned}
& S_{12}=S_{21}= \pm \frac{f(p)}{g(s)} \\
& S_{22}=-(-1)^{k} \frac{h(-p)}{g(p)}
\end{aligned}
$$

Note that, $k$ is an integer that specifies the order of the zeroes of the transmission at the origin. To measure the matching quality between the $50 \Omega$ load and the active device, the transducer power gain (TPG) is calculated. The TPG can be expressed as follows:

$$
\operatorname{TPG}(\omega)=\frac{\left|S_{21}\right|^{2}\left(1-\left|\Gamma_{L}\right|^{2}\right)}{\left|1-S_{11} \Gamma_{L}\right|^{2}}
$$

where, $\Gamma_{L}$ is the normalized load reflection coefficient. For the lossless condition of the equalizer network, $\left|S_{21}\right|^{2}$ can be written as follows:

$$
\left|S_{21}\right|^{2}=1-\left|S_{11}\right|^{2}=\frac{|f(p)|^{2}}{g(p) g(-p)}
$$

where $g(p) g(-p)=h(p) h(-p)+f(p) f(-p)$

Thus, by substituting these values in (7), the TPG becomes:

$$
T P G(\omega)=\frac{[f(p) f(-p)]\left(1-\left|\Gamma_{L}\right|^{2}\right)}{h(p) \cdot h(-p) \cdot\left[1+\left|\Gamma_{L}\right|^{2}\right]+f(p) f(-p)-2 \operatorname{real}\left[\Gamma_{L} \cdot h(p) g(-p)\right]}
$$

Then, the TPG is maximized as flat as possible over the band of interest using the least square method. The optimized coefficients of $h(p)$ corresponding to the optimized performance are calculated. The error function $\delta$ can be written as:

$$
\delta=\sum_{i=1}^{m} T\left(\omega_{i}\right)-T_{0}
$$

where $T_{\left(\omega_{i}\right)}$ represents the transducer power gain at the frequency $\omega_{i}, T_{0}$ is the desired flat gain level and $\mathrm{m}$ is the number of the sampling frequency over the passband. The TPG is then calculated using (9). The error is minimized by updating the coefficient of the polynomial $h(p)$. The increment of $\Delta \mathrm{h}$ is found by applying the Levenberg Marquard technique. When the final form of $S_{11}$ is completed then the matching network is synthesized using the low pass ladder synthesis with the resistive termination.

\subsection{Output matching network}

The output matching network (OMN) is designed by employing the SRFT algorithm. The optimum impedance is obtained from the load-pull method. The optimum impedances are used for the designing of OMN. First of all, the frequency is normalized on the basis of the highest frequency of passband. Then, the output impedance is converted into the reflection coefficient by using $50 \Omega$ characteristic impedance. The initial value of all the coefficients of the polynomial $h(p)$ was assumed -1 . The order of the matching network was chosen to be 4 . After that, the SRFT algorithm is applied to find a flat response over the whole band. When the desired flat response is achieved corresponding to the final value of the coefficient of the polynomial, $h(p)$ is also found. TPG of the output matching network is shown in Figure 2(a). If the coefficient of the polynomial $h(p)$ is known then the value of the polynomial $g(p)$ can also be calculated easily. The scattering parameter $S_{11}$ was used to find the normalized input impedance of the equalizer using the (11).

$$
Z(p)=\frac{1+S_{11}(p)}{1-S_{11}(p)}
$$


The low pass ladder LC synthesis technique is used to find the normalized value of the passive components. The normalized and denormalized passive component values are shown in the Table 3 . The lump elements work very well at the low frequency but at the microwave frequency, the passive lump elements create two problems. Firstly, the lump elements are available in the limited range of values and the implementation of the lumped element at high frequency is very difficult. Secondly, the distance between the lump components is not negligible [18]. To solve this problem, Richard's transformation is used to transform the lump components into the ideal transmission line whereas Kuroda's identities are used to separate the elements by adding the transmission line. The performance of this transformation process is very accurate as the lump component. However, the implementation of this process is a little bit hard. So, a relatively easy way of transforming the lump elements to the microstrip line is called a stepped impedance technique [10]. The performances of this stepped impedance method are similar to the previous Richard's transformation and Kuroda's identities method but not very accurate due to the approximate equivalent circuit is used in this stepped impedance technique. In this stepped impedance technique, the series inductors are replaced by the high impedance transmission line section and the shunt capacitors are replaced by the low impedance transmission line section [18]. Finally, the ideal transmission line is converted into the microstrip line. The performances of the RFPA are optimized using the optimization technique in the keysight advanced design system (ADS) software that is used in the design process. The final OMN is shown in Figure 3.

Table 3. Normalized and denormalized passive components value of OMN

\begin{tabular}{ccc}
\hline Passive component & Normalized value & Denormalized value \\
\hline C1 & 0.8190 & $0.606 \mathrm{pF}$ \\
L2 & 0.5653 & $1.05 \mathrm{nH}$ \\
C3 & 2.2673 & $1.68 \mathrm{pF}$ \\
L4 & 0.9165 & $1.70 \mathrm{nH}$ \\
\hline
\end{tabular}

\subsection{Input matching network}

The input matching network (IMN) is consists of a stability network and matching network. The stability network is very important for a high power amplifier because high power oscillations can damage the active device [18]. The stability of the RFPA can be checked by using Rollett's stability factor K greater than 1 and the magnitude of delta must be less $1[19,20]$. The stability of the power amplifier is determined from the S-parameters [21]. Two popular techniques for stabilizing the circuit are parallel RC and series RC stabilization circuit [22]. In Figure 3, resistor $34.3 \Omega$ and capacitor $6 \mathrm{pF}$ are used parallelly to stabilized RFPA. The IMN is also designed using the same algorithm SRFT. In this case, the input of the $h(p)$ polynomial is initialized for the fourth-order lowpass LC matching network but the TPG performance is not good over the band. Therefore, the order of the lowpass matching network was increased to six. The same procedure is repeated for the order of six and achieved good performance over the entire bandwidth. The TPG versus the normalized frequency is shown in Figure 2(b). After that, the input reflection coefficient $S_{11}(p)$ is determined from the polynomial $h(p)$. Then, the input impedance is calculated from the reflection coefficient by using (11). The normalized matching network is extracted from the input impedance using the lowpass ladder synthesis. The normalized and the denormalized values of the lump components are shown in Table 4. The final input matching network is shown in Figure 3.

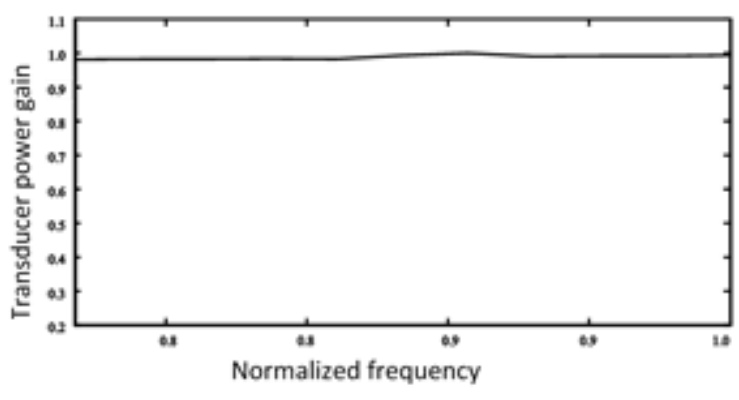

(a)

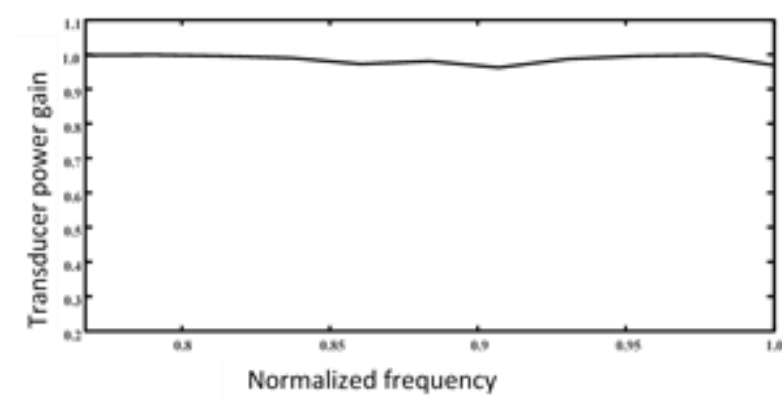

(b)

Figure 2. Transducer power gain vs normalized frequency for, (a) output matching network, (b) input matching network 


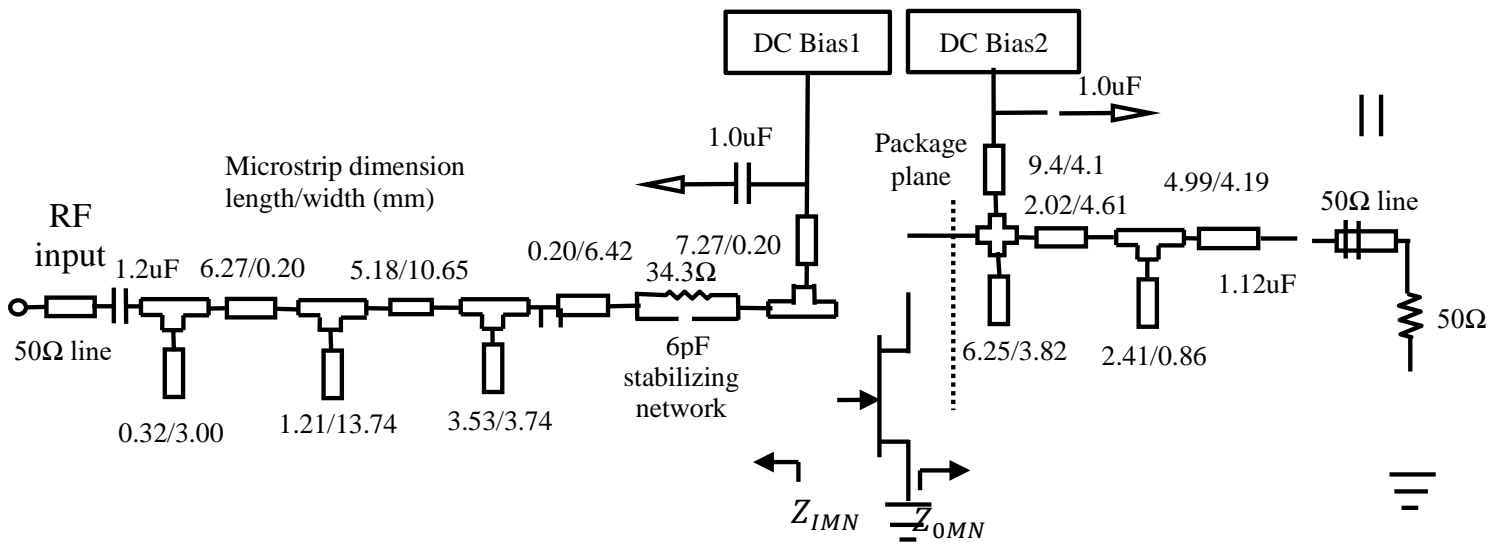

Figure 3. Complete circuit diagram of proposed RFPA

Table 4. Normalized and denormalized passive components value of IMN

\begin{tabular}{ccc}
\hline Passive component & Normalized value & Denormalized value \\
\hline L1 & 0.5702 & $1.06 \mathrm{nH}$ \\
C2 & 6.2069 & $4.59 \mathrm{pF}$ \\
L3 & 0.9953 & $1.84 \mathrm{nH}$ \\
C4 & 1.4088 & $1.04 \mathrm{pF}$ \\
L5 & 1.4583 & $2.70 \mathrm{nH}$ \\
C6 & 0.9816 & $0.727 \mathrm{pF}$ \\
\hline
\end{tabular}

\section{PERFORMANCES OF THE PROPOSED RFPA}

In the design of this RFPA, Rogers RO3006C substrate board with dielectric constant $\varepsilon_{r}=6.5$ and thickness of $1.28 \mathrm{~mm}$ are used. The gate of the $\mathrm{GaN}$ device is biased at $-3.1 \mathrm{~V}$ which corresponding to the drain current of $33 \mathrm{~mA}$ and the drain voltage is $28 \mathrm{~V}$, as suggested by the datasheet. The RFPA is tested with continuous wave $(\mathrm{CW})$ excitation at the frequency range of 3.3 to $4.3 \mathrm{GHz}$. The proposed RFPA is simulated using Keysight ADS. The voltage and current waveform at the intrinsic plane for $3.3 \mathrm{GHz}$ and 4.3 $\mathrm{GHz}$ are obtained using the de-embedding network shown in Figure 4. The de-embedding network is extracted from S-parameter provided by Cree company [23]. The performances of the proposed RFPA for the whole frequency band are shown in Figure 5(a). It is seen that the efficiency is greater than $70.7 \%$ all over the frequency band with a maximum of $81.5 \%$. The maximum power-added efficiency (PAE) is $75.0 \%$ at $3.5 \mathrm{GHz}$. The PAE is greater than $63.7 \%$ between the $3.3 \mathrm{GHz}$ to $4.3 \mathrm{GHz}$. The output power is in the range from 40.0 to $41.0 \mathrm{dBm}$. The gain is $10-11 \mathrm{~dB}$ over the entire band at $30 \mathrm{dBm}$ input power. The performances of RFPA at different input power levels are also shown in Figure 5(b). The PAE and the drain efficiency increases with the increase of input power. The gain and the output power decrease with the increase of the input power. However, at the higher input power, the amplifier becomes saturated and the efficiency does not increase linearly. The comparison between the proposed RFPA and the state-ofthe-art broadband power amplifiers are listed in Table 5. It can be seen from Table 5 that the proposed RFPA presents the highest efficiency.

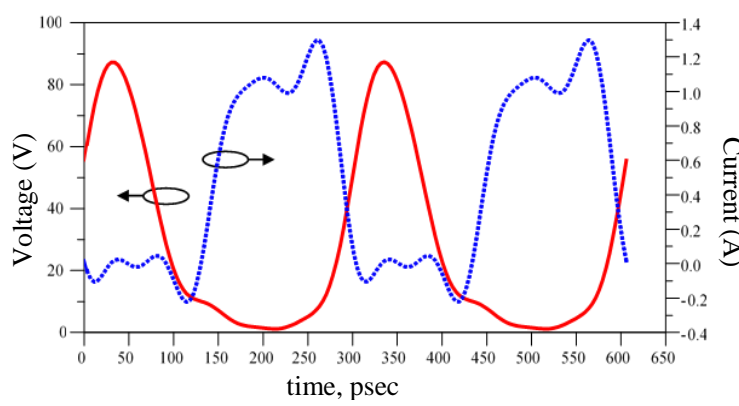

(a)

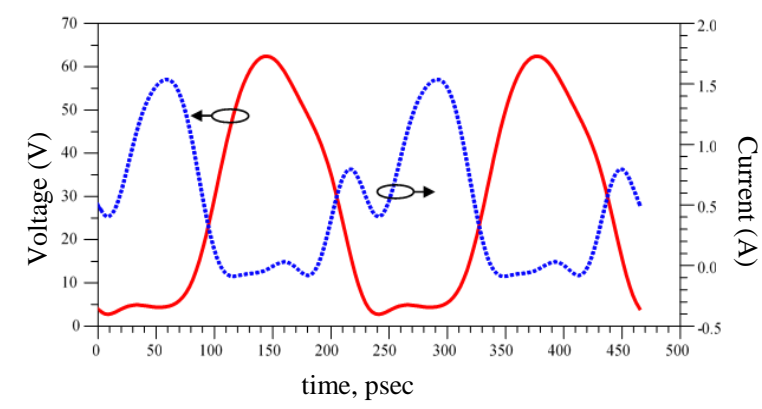

(b)

Figure 4. Voltage and current waveform, (a) At $3.3 \mathrm{GHz}$, (b) $4.3 \mathrm{GHz}$ at the drain plane 


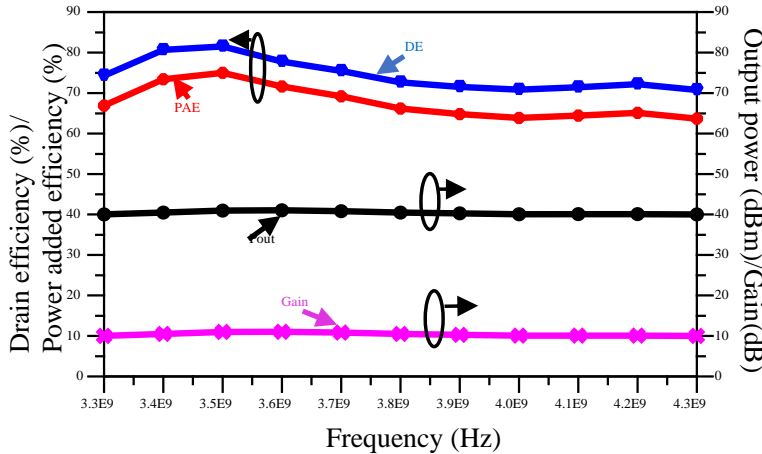

(a)

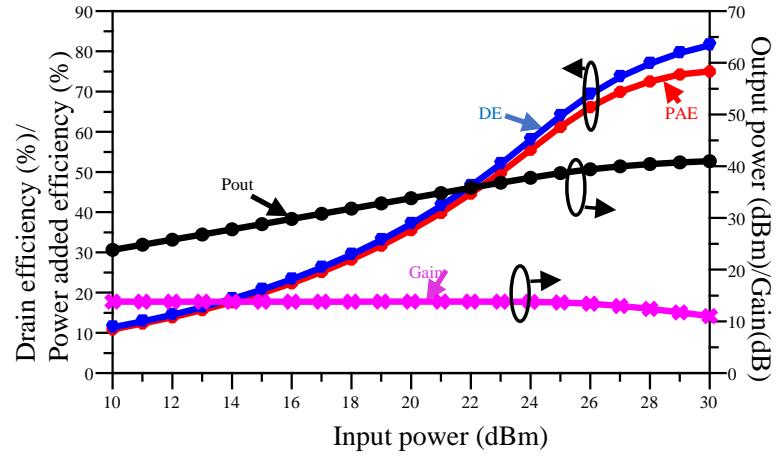

(b)

Figure 5. Performance of the power amplifier (a) Different frequency and (b) Different input power

Table 5. State-of-the-art comparison of broadband RFPA

\begin{tabular}{cccccccc}
\hline Ref & Device & PA type & Bandwidth $(\mathrm{GHz})$ & DE & Gain $(\mathrm{dB})$ & Output Power & Year \\
\hline$[9]$ & CGH27015F & CCF & 1.52 .5 & $60-75 \%$ & $9.5-127$ & $9-14 \mathrm{~W}$ & 2017 \\
{$[8]$} & CGHV40030F & ECCF & $0.2-2.5$ & $55.5-70.3 \%$ & $11.7-14.2$ & $43.7-46.9 \mathrm{dBm}$ & 2017 \\
{$[24]$} & CGH40010F & CF & $1.1-2.1$ & $60-73 \%$ & $10-15$ & $9-11 \mathrm{w}$ & 2016 \\
{$[25]$} & CGH27015F & CCF & $1.4-2.4$ & $60-73 \%$ & $10.1-11.1$ & $>40 \mathrm{dBm}$ & 2016 \\
{$[26]$} & CGH40010F & CCF & $1.2-3.6$ & $60-72 \%$ & $10.5-12.5$ & $40-42.2 \mathrm{dBm}$ & 2018 \\
This work & CGH40010F & CCF & $3.3-4.3$ & $70.7-81.5 \%$ & $10-11$ & $40-41 \mathrm{dBm}$ & 2019 \\
\hline
\end{tabular}

CF: Class-F, CCF: Continuous class-F, ECCF: Extended continuous class-F

\section{CONCLUSION}

To implement the 5G network, a high efficiency RFPA is required. In this paper, the CCF mode RFPA has been designed for the new frequency range between $3.3 \mathrm{GHz}$ to $4.3 \mathrm{GHz}$. The target impedance for fundamental and harmonics frequency was realized by using the SRFT algorithm. The designed amplifier achieved a very good performance. It shows that the maximum drain efficiency is $81.5 \%$ at $3.5 \mathrm{GHz}$. The gain of the RFPA is also greater than $10 \mathrm{~dB}$ over the entire frequency band. The output power is larger than $40 \mathrm{dBm}$ which is very good because the $10 \mathrm{~W}$ device is used. The proposed RFPA will be implemented in hardware. It is expected that hardware performance will be the same as simulation.

\section{ACKNOWLEDGEMENTS}

The authors would like to acknowledge the MMM-GRA fund no: MMUI/ 180270.02 of Multimedia University for funding this activity as well as Wolf speed, A Cree Company for providing large-signal Model of CGH40010F.

\section{REFERENCES}

[1] G. Ancans, V. Bobrovs, A. Ancans, and D. Kalibatiene, "Spectrum Considerations for 5G Mobile Communication Systems,” Procedia Computer Science, vol. 104, pp. 509-516, December 2016.

[2] "5G Frequency Bands-everything RF," [Online]. Available: https://www.everythingrf.com/community/5gfrequency-bands-in-europe. [Accessed: 29-Jul-2019].

[3] "5G Frequency Bands-everything RF," [Online]. Available: https://www.everythingrf.com/community/5gfrequency-bands. [Accessed: 19-Aug-2019].

[4] "Crucial Metric for 5G and IoT | Mouser," [Online]. Available: https://my.mouser.com/applications/rf-poweramplifier-efficiency-for-5g-iot/. [Accessed: 06-May-2019].

[5] S. Fazel and J. Javidan, "A Highly Efficient and Linear Class AB Power Amplifier for RFID Application," Bulletin of Electrical Engineering and Informatics, vol. 4, no. 2, pp. 147-154, 2015.

[6] K. S. Tsang, "Class-F Power Amplifier with Maximized PAE," M.S. thesis, California Polytechnic State University, San Luis Obispo, United States, 2010.

[7] S. Y. Zheng, Z. W. Liu, X. Y. Zhang, X. Y. Zhou and W. S. Chan, "Design of Ultrawideband High-Efficiency Extended Continuous Class-F Power Amplifier," in IEEE Transactions on Industrial Electronics, vol. 65, no. 6, pp. 4661-4669, June 2018. 
[8] H. Huang, B. Zhang, C. Yu, J. Gao, Y. Wu and Y. Liu, "Design of Multioctave Bandwidth Power Amplifier Based on Resistive Second-Harmonic Impedance Continuous Class-F," in IEEE Microwave and Wireless Components Letters, vol. 27, no. 9, pp. 830-832, Sept. 2017.

[9] E. Aggrawal, K. Rawat and P. Roblin, "Investigating Continuous Class-F Power Amplifier Using Nonlinear Embedding Model," in IEEE Microwave and Wireless Components Letters, vol. 27, no. 6, pp. 593-595, June 2017.

[10] N. Babapour and J. Javidan, "Design of a Class F Power Amplifier With 60\% Efficiency at $1800 \mathrm{MHz}$ Frequency," Bulletin of Electrical Engineering and Informatics, vol. 4, no. 4, pp. 314-319, 2015.

[11] N. Tuffy, L. Guan, A. Zhu and T. J. Brazil, "A Simplified Broadband Design Methodology for Linearized HighEfficiency Continuous Class-F Power Amplifiers," in IEEE Transactions on Microwave Theory and Techniques, vol. 60, no. 6, pp. 1952-1963, 2012.

[12] M. G. Sadeque, Z. Yusoff, M. Roslee and N. S. R. Hadi, "Design of a Broadband Continuous Class-F RF Power Amplifier for 5G Communication System," 2019 IEEE Regional Symposium on Micro and Nanoelectronics (RSM), Genting Highland, Pahang, Malaysia, pp. 145-148, 2019.

[13] Z. Lu and W. Chen, "Resistive Second-Harmonic Impedance Continuous Class-F Power Amplifier With Over One Octave Bandwidth for Cognitive Radios," in IEEE Journal on Emerging and Selected Topics in Circuits and Systems, vol. 3, no. 4, pp. 489-497, Dec. 2013.

[14] B. S. Yarman, "Design of ultra-wideband antenna matching networks," 2007 IEEE Applied Electromagnetics Conference (AEMC), Kolkata, pp. 1-4, 2007.

[15] B. S. Yarman and H. J. Carlin, "A Simplified "Real Frequency" Technique Appliable To Broadband Multistage Microwave Amplifiers," 1982 IEEE MTT-S International Microwave Symposium Digest, Dallas, TX, USA, pp. 529-531, 1982.

[16] Hongming An, B. K. J. C. Nauwelaers and A. R. van de Capelle, "Broadband microstrip antenna design with the simplified real frequency technique," in IEEE Transactions on Antennas and Propagation, vol. 42, no. 2, pp. 129-136, Feb. 1994.

[17] B. S. Yarman, N. Retdian, S. Takagi and N. Fujii, "Gain-Bandwidth Limitations of $0.18 \mu \mathrm{m}$ Si-CMOS RF technology," 2007 18th European Conference on Circuit Theory and Design, Seville, pp. 264-267, 2007.

[18] D. M. Pozar, "Microwave Engineering," Second Edi. JOHN WILEY \& SONS.INC, 1998.

[19] S. Nawaz and H. Mehmood, "Stabilization of Microwave Amplifiers," 2005 Pakistan Section Multitopic Conference, Karachi, pp. 1-4, 2005.

[20] G. Gonzalez, "Microwave Transistor Amplifier Analysis and Design," Prentice-Hall, Inc. Division of Simon and Schuster One Lake Street Upper Saddle River, NJ, United States, September 1996.

[21] A. Rachakh, L. El Abdellaoui, J. Zbitou, A. Errkik, A. Tajmouati, and M. Latrach, "A two-stages microstrip power amplifier for WiMAX applications," TELKOMNIKA Telecommunication Computing Electronics and Control., vol. 16 , no. 6, pp. 2500-2506, 2018.

[22] Muhammed Hakan Yilmaz, "Design of a wideband 10W GaN power amplifier," M.S. thesis, Department of Electronics and Telecommunications, Faculty of Information Technology, Mathematics and Electrical Engineering, Norwegian University of Science and Technology, Trondheim, Ålesund, Gjøvik, Norway, July 2011.

[23] V. Carrubba, "Novel Highly Efficient Broadband Continuous Power Amplifier Modes," M.S. thesis, Division of Electrical Engineering, School of Engineering, Cardiff University, Cardiff, Wales, United Kingdom, pp. 1-356, August 2012.

[24] M. Iqbal and A. Piacibello, "GaN HEMT based class-F power amplifier with broad bandwidth and high efficiency," 2016 International Conference on Integrated Circuits and Microsystems (ICICM), Chengdu, pp. 131-134, 2016.

[25] E. Aggrawal, S. Saxena and K. Rawat, "Broadband power amplifier design by exploring design space of continuous class-F mode," 2016 Asia-Pacific Microwave Conference (APMC), New Delhi, pp. 1-4, 2016.

[26] C. Huang, S. He, W. Shi and B. Song, "Design of Broadband High-Efficiency Power Amplifiers Based on the Hybrid Continuous Modes With Phase Shift Parameter," in IEEE Microwave and Wireless Components Letters, vol. 28, no. 2, pp. 159-161, Feb. 2018.

\section{BIOGRAPHIES OF AUTHORS}

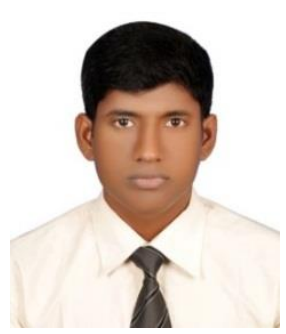

Md. Golam Sadeque has received B. Sc. Eng. degree in Electrical and Electronics Engineering (EEE) from Rajshahi University of Engineering and Technology (RUET) in 2010. He is pursuing master of engineering science (M. Eng. Sc,) degree under faculty of engineering at Multimedia University. He is also working as an assistant professor (on study leave) since 23 June 2015 to till now in the department of Electrical and Electronic Engineering at Pabna University of Science and Technology (PUST), Pabna-6600, Bangladesh. His research interest includes design of Radio frequency power amplifier (RFPA) and Biomedical engineering. Email: 1181401494@student.mmu.edu.my,golamsadeq@gmail.com 


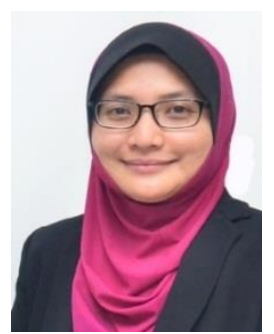

Dr Zubaida Yusoff holds the position of a Senior Lecturer at the Faculty of Engineering, Multimedia University. She received her B.Sc. in Electrical and Computer Engineering (cum laude with distinction) and M.Sc. in Electrical Engineering from The Ohio State University, USA in 2000 and 2002 respectively. She worked with Telekom Malaysia International Network Operation in 2002 before she joined Multimedia University in 2004. She continued her studies at Cardiff University, Wales, UK in 2008 and received Ph. D degree in 2012. Dr Zubaida has presented technical papers at conference nationally and internationally. One of her conference papers has received "Honorable Mention" for the Student Paper Competition at the International Microwave Symposium, USA in 2011. She has authored/co-authored more than 25 journals and conference papers. Her teaching and research focus in the area of Microelectronics, Analog/Mixed Signal RF Circuit Design and Microwave/mm-wave Power Amplifier System.

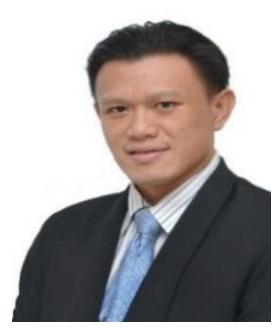

Associate Professor Dr. Mardeni Roslee is an academician under Faculty of Engineering, Multimedia University, Cyberjaya, Malaysia. At Multimedia University, he is a current Deputy Director of Research Institute of Digital Connectivity, Chair of Centre of Wireless Technology and Chief Executive Officer (CEO) and Founder of Armada company. He serves as current Chair of IEEE Malaysia Comsoc/VTS, which is for recognized and selected members in professional organization, networking and interaction with like-minded multidisciplinary professionals. His current research interests are 5G/6G telecommunication, D2D, satellite, Internet of Things and radar communication. He has published over 90 indexed international journals and conference papers. He has 34 completed PhD and Masters and 10 ongoing postgraduate students. His contributions to academic and the engineering professional over the years have earned him recognitions nationally and internationally, he has awarded various international/local awards including being awarded the University Excellent Researcher Award for 2016 and 2018, respectively. 